\title{
Experimental Analyses of Mechanical Performance of CFST Column to Assembled Steel H-Beam Connections
}

\author{
Cui Chunyi ${ }^{*}, 1,3$, Zhao Jinfeng ${ }^{2}$, Zhang Yannian ${ }^{2}$ and Zuo Wenxin ${ }^{3}$ \\ ${ }^{I}$ Department of Civil Engineering, Dalian Maritime University, Dalian 116026, China \\ ${ }^{2}$ School of Civil Engineering, Shenyang Jianzhu University, Shenyang 110168, China \\ ${ }^{3}$ School of Civil and Mechanical Engineering, University of Birmingham, Birmingham, B15 2TT, United Kingdom
}

\begin{abstract}
The mechanical performance of a new proposed type of cross-shaped connection with concrete-filled steel tubular (CFST) column and assembled steel H-beam was investigated. Cyclic loading tests on the cross-shaped connections are carried out by using MTS servo loading system. Comparative analyses are conducted based on the experimental results including hysteretic curves, skeleton curves and stiffness degradation curves as well as ductility coefficients of cyclic loading tests. Furthermore, effects of geometric parameters of ring-stiffened plate, axial compression ratio and backing plate on the deformation performance of cross-shaped connections are analyzed. The results show that the increase of width of ring plate and the shape change of ring plate from square to circle can both significantly improve the ductility and the hysteretic characteristics of connection. It is emphasized that the specimen with square ring plates is of better deformation performance but lower bearing capacity than the ones with circular ring plates. Besides, the backing plates always have positive effects on the hysteretic characteristics, ductility and energy dissipation of the CFST column connections. Conversely, the increase of axial compression ratio contributes negatively to both the bearing capacity and deformation performance of the connection specimens. It can be concluded that the presented cross-shaped connection is of good deformation performance relating to hysteretic characteristics, energy dissipation and ductility, which can provide reference towards engineering practice with potential perspective application.
\end{abstract}

Keywords: Cross-shaped connection, cyclic loading, ductility, hysteretic behavior.

\section{INTRODUCTION}

In the last thirty years, concrete-filled steel tubular (CFST) columns were widely employed as compression members in high-rise building, long-span bridge and underground structures due to the advantages of good performance, construction convenience and fine fire resistance as well as lower construction cost [1,2]. It is wellknown that concrete-filled steel tubular columns increase the strength and the stiffness of the section by confining the concrete panel in the steel tube. With the application of CFST columns into engineering practices, different types of connections have been developed to connect flange beams to tube columns [3]. According to the 'Specification for design and construction of steel pipe concrete structure (CECS28:90)', beam-column connections should be of fine entirety and satisfy the criterion of strong column and weak beam. The corresponding modes of load transfer and construction technology are two key aspects of connection design, as emphasized by RICLES and GREGORY et al. [4, 5]. Researchers have conducted many studies on CFST column and beam connections. As an effective experimental measure, cyclic loading tests are adopted by most researchers

*Address correspondence to this author at the Department of Civil Engineering, Dalian Maritime University, Dalian 116026, China;

Tel: 0086-422-84724283; Fax: 0086-411-84724283;

E-mail: cuichunyi@dlmu.edu.cn in analyzing deformation capacity of CFST column-beam connections. Typically, seismic performances of concrete-filled steel square tube column connections with $\mathrm{H}$ beams was investigated by MORINO et al. [6]. And the ductility and energy dissipation of concrete-filled steel square tubular column connections were discussed in $[7,8]$. Furthermore, both the characteristics of stress concentration and plastic hinge in embedded type of CFST column connections were reported by BEUTEL et al. and Li et al. respectively [9, 10]. Based on previous engineering practice and research, effects of geometric features of connections, axial compression ratio and other factors on the performance of CFST column connections such as ductility and hysteretic characteristics were discussed in [1115]. However, most presented types of CFST column connections are connected by welding technique, this may lead to construction inconvenience and inefficiency especially for the complicated frameworks and structures. Whereas, fabricated beams with connector of high strength friction grip bolt are promising for designing CFST column connections, which is of easy operation and can satisfy the strength needs as well. In addition, there was little research on CFST column connections with assembled beams without welding both in theoretical analysis and experimental investigation.

The main purposes of this work are to propose and design a new type of cross-shaped connection with CFST column and assembled steel H-beam and to carry out cyclic loading tests by using MTS servo loading system. On the basis of experimental results, comparative analyses are also 
conducted to discuss the effects of geometric parameters of ring-stiffened plate, axial compression ratio and backing plate on the deformation performance of cross-shaped connections.

\section{DESIGNED CONNECTION AND EXPERIMENTAL PROGRAM}

\subsection{Designed Connection and Test Specimens}

The details of the connections used in this research are shown in Fig. (1), in which both the three-dimensional

(a) 3D Configurations of typical specimens

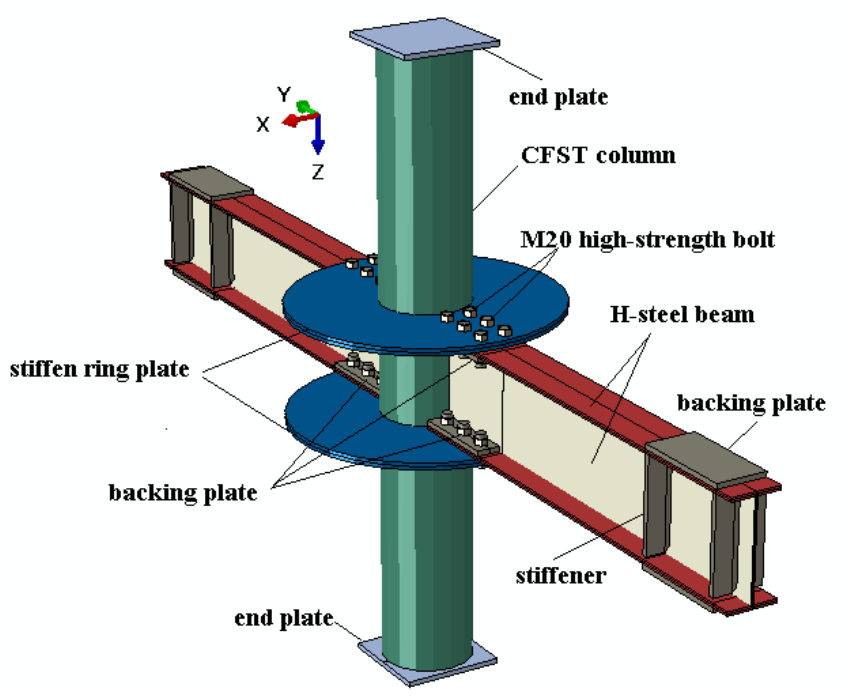

(b) Sectional views of connection

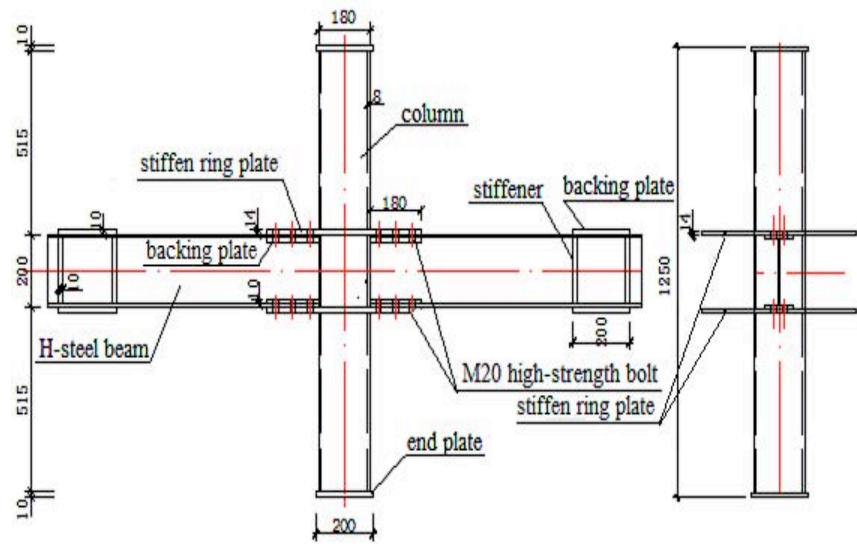

Fig. (1). Details of connection. configurations and the sectional views of connection are depicted. The types of steel used in the specimens include Q235, Q345, Q390 and Q420, and the strengths of all types are obtained by tensional coupon tests. The detailed steel properties of specimens are listed in Table $\mathbf{1}$. The designed strength grade of filled-concrete is $\mathrm{C} 60$ and the corresponding average value of compressive strength for $150 \mathrm{~mm}$ cube specimen is $f_{\mathrm{cu}}=64 \mathrm{MPa}$. Six specimens were manufactured according to the schedule of specimens listed in Table 2. Especially, square ring plate was adopted in the specimen F12D3, of which the diagonal line coincides with the median of H-beam. All H-beams of connection specimens were attached to CFST column stubs by high strength steel bolts as cantilevers.

\subsection{Test Set-Up}

Cyclic loading tests on the cross-shaped connections are carried out by using MTS servo loading system. The test set-up and loading system of the connection experiments are shown in Fig. (2).

The dual actuators were controlled by computer intelligent system. Test results could be gathered by the system automatically as well. The column was assumed to be pin-supported at the end and the beam was loaded at an assumed pin at the position of actuators. The distance measured from the column centerline to the loading point of actuator was $900 \mathrm{~mm}$. As shown in Fig. (3), strain gauges were applied to the specimens in order to measure strain distributions and principal strain magnitudes and directions at typical points. Fig. (4) shows the displacement transducers (DT) employed to measure the beam tip displacement and rotation contributions of different parts of the specimens.

The axial force for CFST column was of $5000 \mathrm{kN}$ magnitude and concident with the central line of itself. The cyclic loading according to a quasi-static cyclic displacement pattern was defined in terms of beam end displacement and was applied vertically through the dual actuators to the $\mathrm{H}$ beams based on the loading scheme adopted in Refs[16]. The loading pattern was applied to each specimen until failure occurred.

\section{EXPERIMENTAL RESULTS AND DISCUSSION}

\subsection{Hysteretic Characteristics}

The hysteretic curves of load versus displacement relationships obtained from the tests are depicted in Fig. (5). It is obvious that the hysteretic characteristics of each specimen become much more robust with the cyclic increase of displacements, which indicates the fine deformation

Table 1. Steel properties of specimens.

\begin{tabular}{|c|c|c|c|c|c|c|}
\hline Specimen & $\begin{array}{c}\text { Thickness } \\
(\mathbf{m m})\end{array}$ & $\begin{array}{c}\text { Yield Strength } \\
\mathbf{( M P a )}\end{array}$ & $\begin{array}{c}\text { Ultimate Stress } \\
\mathbf{( M P a )}\end{array}$ & $\begin{array}{c}\text { Elastic Modulus } \\
\text { (MPa) }\end{array}$ & $\begin{array}{c}\text { Poision } \\
\text { Ratio }\end{array}$ & $\begin{array}{c}\text { Elongation } \\
\mathbf{( \% )}\end{array}$ \\
\hline \hline Tube shell & 8 & 294.6 & 386.7 & $1.9 \times 10^{5}$ & 0.29 & $20.6 \%$ \\
\hline H-beam flange & 8 & 310.3 & 432.8 & $2.1 \times 10^{5}$ & 0.24 & $22.1 \%$ \\
\hline H-beam web & 5.5 & 370.6 & 496.7 & $2.0 \times 10^{5}$ & 0.28 & $21.4 \%$ \\
\hline Stiffen ring plate & 14 & 272.2 & 410.7 & $1.9 \times 10^{5}$ & 0.28 & $24.6 \%$ \\
\hline Backing plate & 10 & 278.6 & 381.6 & $2.1 \times 10^{5}$ & 0.27 & $23.6 \%$ \\
\hline
\end{tabular}


Table 2. Schedule of specimens.

\begin{tabular}{|c|c|c|c|c|c|c|c|}
\hline \multirow{2}{*}{ Specimen } & \multirow{2}{*}{$\begin{array}{l}\text { Backing } \\
\text { Plate }\end{array}$} & \multicolumn{2}{|c|}{ Column (mm) } & \multicolumn{2}{|c|}{ H-Beam (mm) } & \multirow{2}{*}{$\begin{array}{c}\text { Axial Compression } \\
\text { Ratio }\end{array}$} & \multirow{2}{*}{$\begin{array}{c}\text { Width of Ring Plate } \\
\text { (mm) }\end{array}$} \\
\hline & & Cross Section & Length & Cross Section & Length & & \\
\hline H18D3 & with & $\phi 180 \times 8.00$ & 1250 & $200 \times 100 \times 8 \times 5.5$ & 2080 & 0.3 & 180 (circular) \\
\hline H18W3 & without & $\phi 180 \times 8.00$ & 1250 & $200 \times 100 \times 8 \times 5.5$ & 2080 & 0.3 & 180 (circular) \\
\hline H18D6 & with & $\phi 180 \times 8.00$ & 1250 & $200 \times 100 \times 8 \times 5.5$ & 2080 & 0.6 & 180 (circular) \\
\hline H18W6 & without & $\phi 180 \times 8.00$ & 1250 & $200 \times 100 \times 8 \times 5.5$ & 2080 & 0.6 & 180 (circular) \\
\hline H12D3 & with & $\phi 180 \times 8.00$ & 1250 & $200 \times 100 \times 8 \times 5.5$ & 2080 & 0.3 & 120 (circular) \\
\hline F12D3 & with & $\phi 180 \times 8.00$ & 1250 & $200 \times 100 \times 8 \times 5.5$ & 2080 & 0.3 & 127(square) \\
\hline
\end{tabular}

(a) Sketch of test set-up of connection

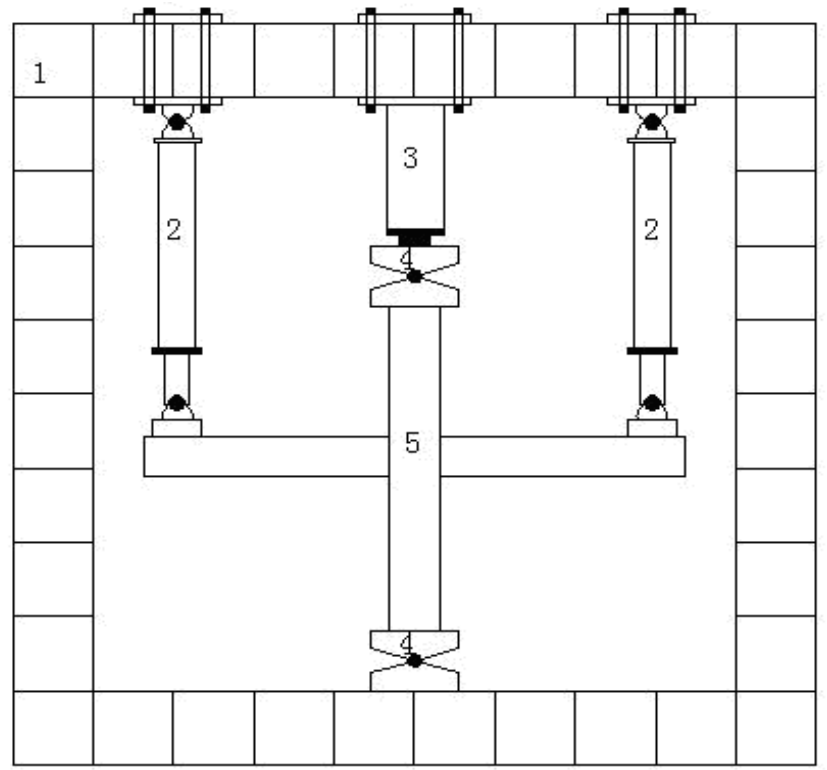

1. Reaction frame; 2. $250 \mathrm{kN} \mathrm{MTS} \mathrm{actuator;} \mathrm{3.} 5000 \mathrm{kN} \mathrm{Jack;}$ 4. Hinge Bearing; 5.Specimen

(b) MTS servo loading system

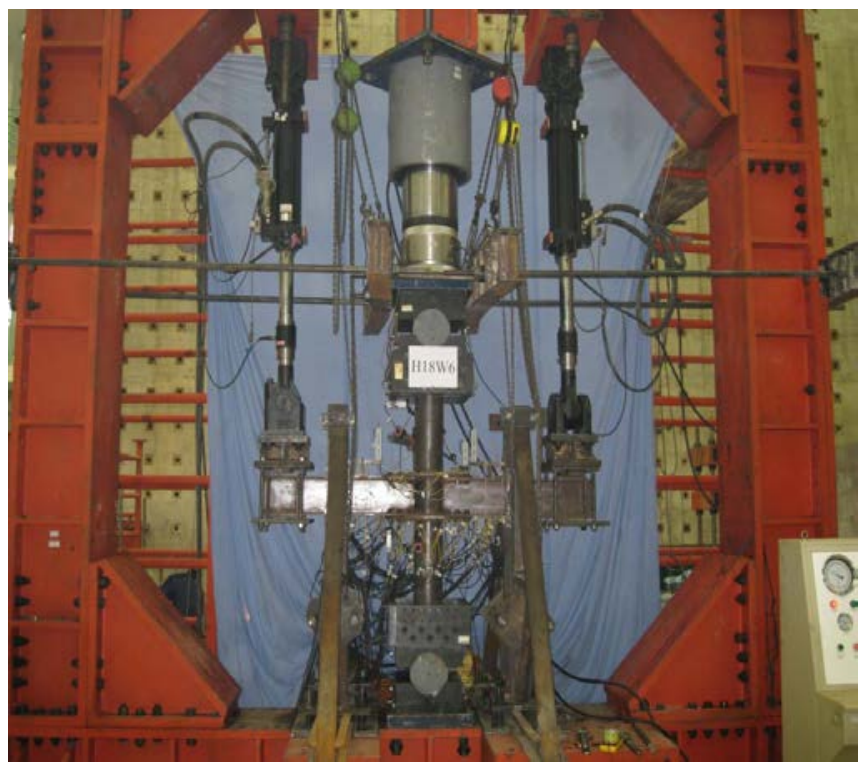

Fig. (2). Test set-up and loading system. (a) a vertical view

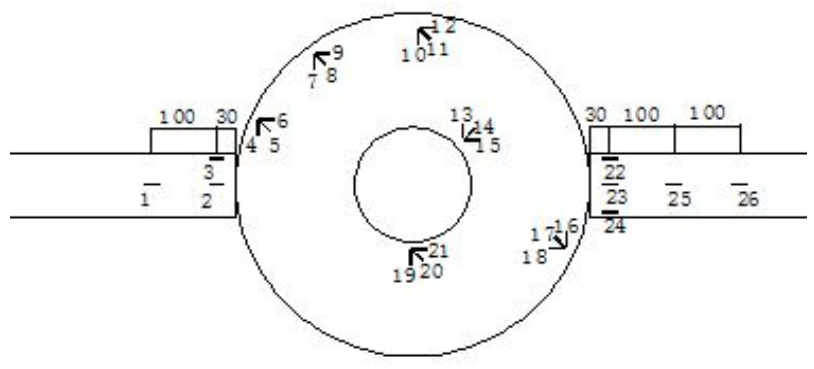

(b) an upward view

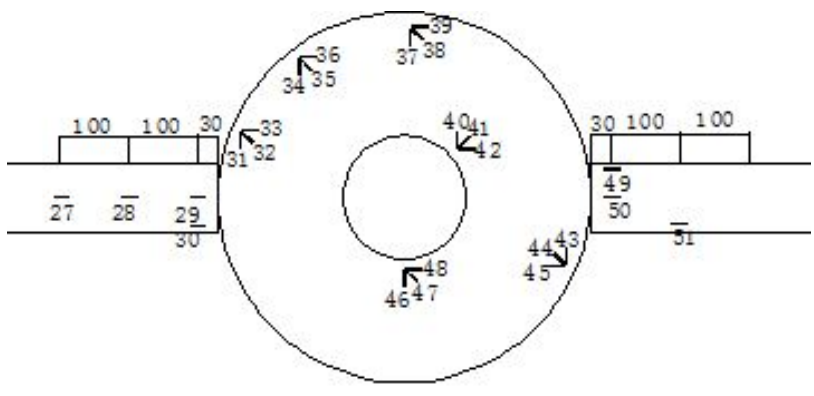

(c) a lateral view

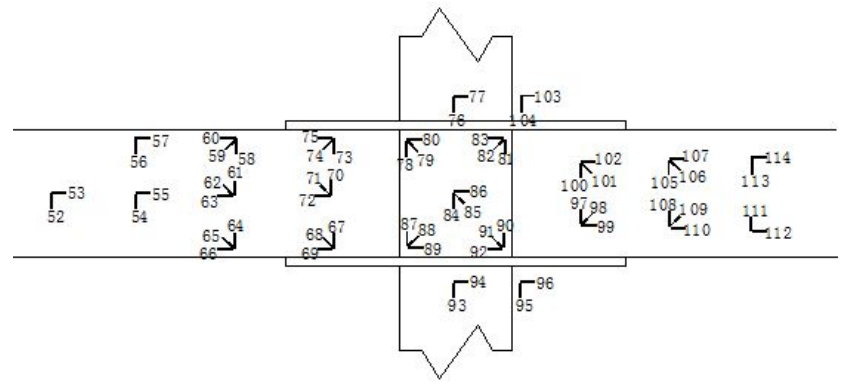

Fig. (3). Distribution of Strain gauges applied to the specimens.

performance of the presented connections. For specimens with axial compression ratio less than or equal to 0.3 , the hardening phase displays longer time until serious buckling. Whereas, for specimens with high axial ratio such as, 0.6 , the hardening phenomena does not become evident. On the basis of the comparison between specimens, it can be also seen that the increase of ring plate width and the installation of backing plate contribute positively to the hysteretic 


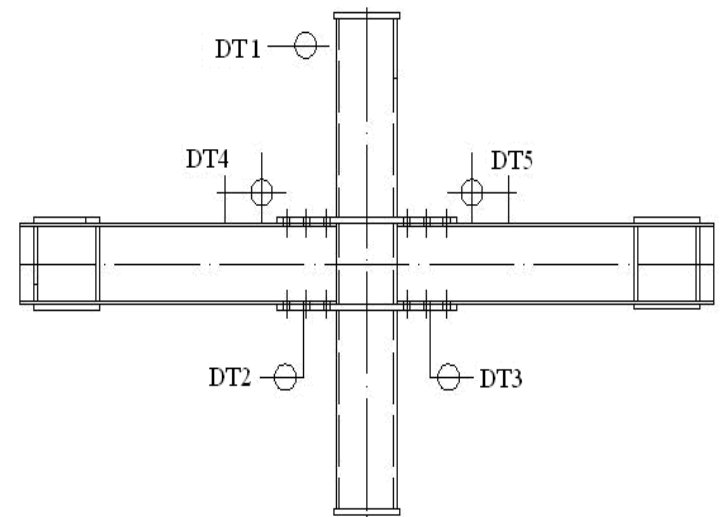

Fig. (4). Distribution of displacement transducers. performance of the connection specimens. Fig. (6) shows the the skeleton curves of load versus displacement relationships. Similarly, it also can be indicated that the increase of ring plate width and the installation of backing plate contribute positively to the deformation capacity of the connection specimens. And the increase of axial compression ratio has negative effects on the bearing capacity and deformation performance of the connection specimens in accordance with what is displayed in the hysteretic curves above. Furthermore, it demonstrates that the specimen with square ring plate presents higher ultimate and failure loads than ones with circular ring plates. Integrated with typical indexes obtained from skeleton curves listed in Table $\mathbf{3}$ it can be seen that, especially, the specimen with square ring plate presents better bearing capacity than ones with circular ring plates but less deformation performance. (a) H18D3

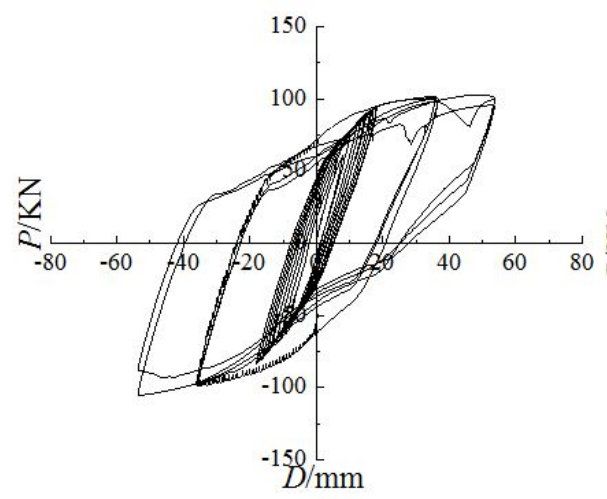

(c) H18D6

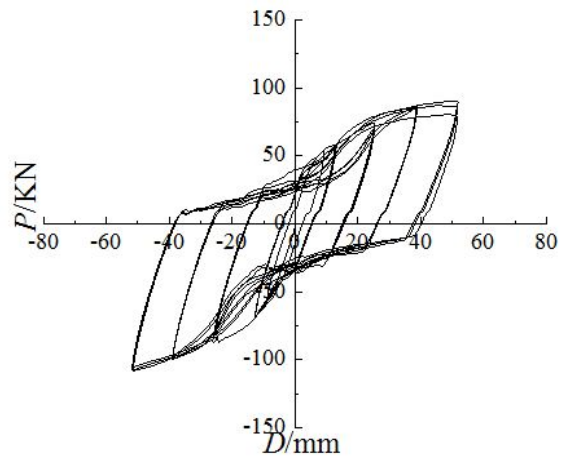

(e) H12D3

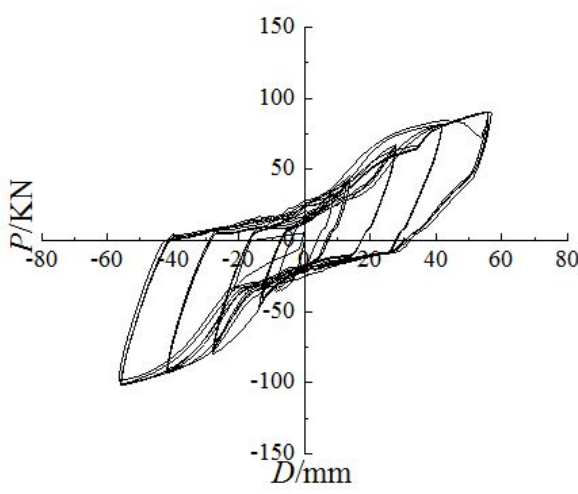

(b) $\mathrm{H} 18 \mathrm{~W} 3$

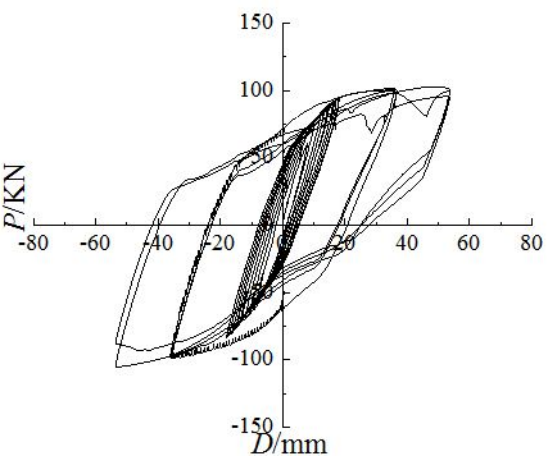

(d) H18W6

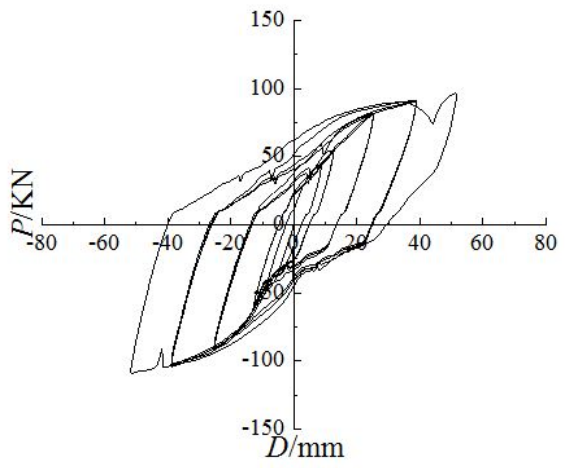

(f) F12D3

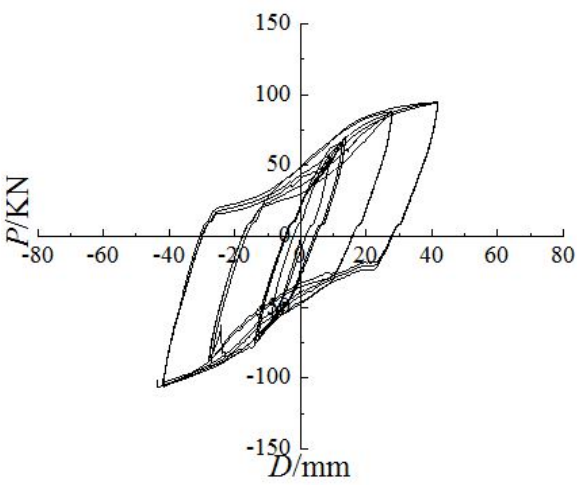

Fig. (5). Comparisons of P- $\Delta$ hysteretic curves of connection specimens. 
(a)

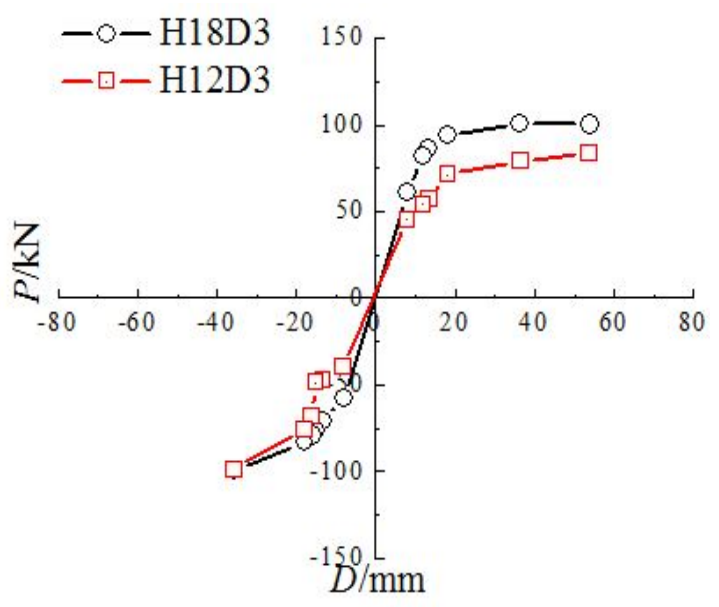

(c)

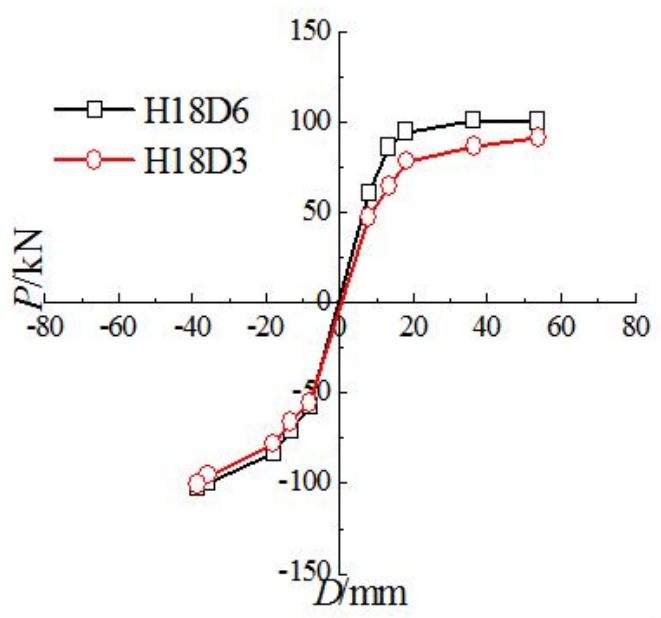

(e)

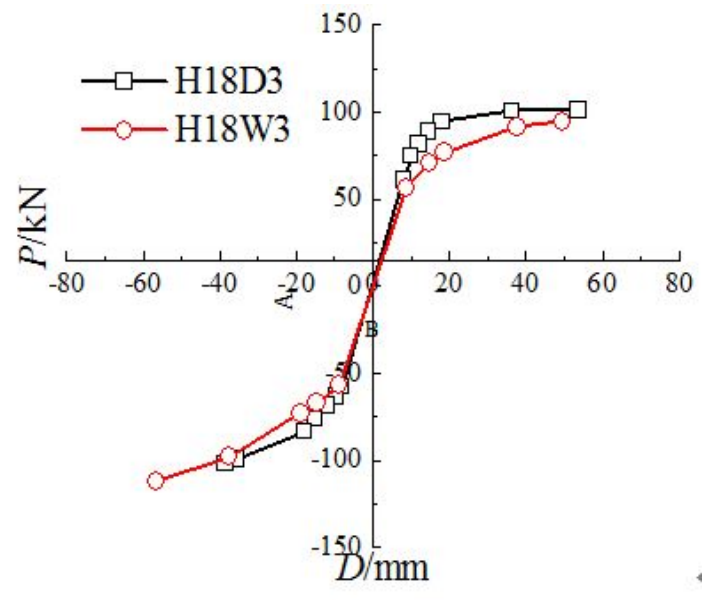

(b)

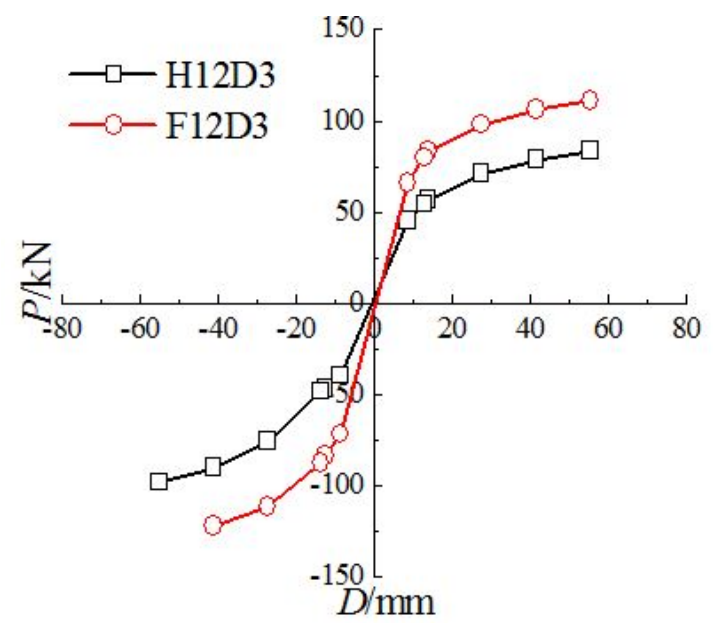

(d)

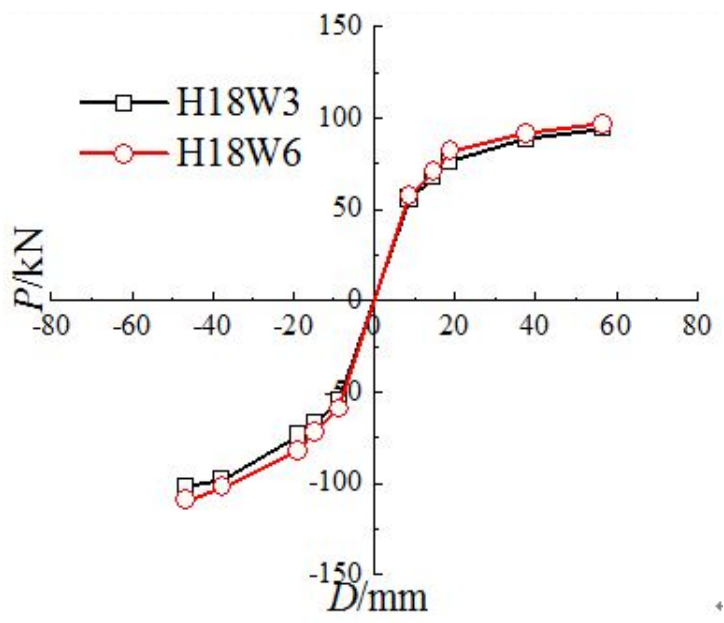

(f)

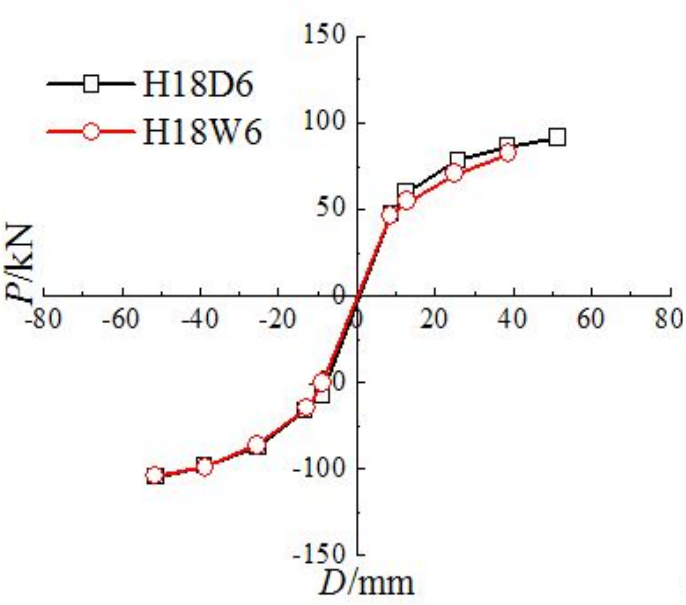

Fig. (6). Comparisons of P- $\Delta$ skeleton curves of connection specimens.

\subsection{Coefficients of Ductility and Energy Dissipation}

In seismic design of structures, ductility coefficients are important indexes to evaluate the performance of structure deformation, as emphasized in Ref. [17]. In the present work, both displacement ductility ratio and rotational ductility coefficient are considered for analyses as listed in
Table 4. Generally, the higher the displacement ductility ratio is the better ductile performance can be. The ductility coefficients obtained from cyclic tests of all connection specimens generally satisfy the needs noted in 'Specification for design and construction of steel pipe concrete structure (CECS28:90)'. It is described that the increase of width of 
Table 3. Typical indexes obtained from skeleton curves of connection specimens.

\begin{tabular}{|c|c|c|c|c|c|c|}
\hline $\begin{array}{c}\text { Connection } \\
\text { Specimen }\end{array}$ & $\begin{array}{c}\text { Yield } \\
\text { Load } \\
\mathbf{P}_{\mathbf{y}}(\mathbf{k N})\end{array}$ & $\begin{array}{c}\text { Displacement } \\
\text { Load } \\
\Delta_{\mathrm{y}}(\mathbf{m m})\end{array}$ & $\begin{array}{c}\text { Ultimate } \\
\text { Load } \\
P_{\max }(k N)\end{array}$ & $\begin{array}{c}\text { Ultimate } \\
\text { Displacement } \\
\Delta_{\max }(\mathrm{mm})\end{array}$ & $\begin{array}{c}\text { Failure } \\
\text { Load } \\
P_{u}(k N)\end{array}$ & $\begin{array}{c}\text { Failure } \\
\text { Displacement } \\
\Delta_{\text {u }}(\mathrm{mm})\end{array}$ \\
\hline H18D3 & 59.48 & 13.92 & 115.92 & 52.96 & 98.53 & 58.52 \\
\hline H18W3 & 56.71 & 12.77 & 112.02 & 56.6 & 95.22 & 59.43 \\
\hline H18D6 & 67.23 & 14.67 & 109.13 & 51.31 & 92.76 & 54.52 \\
\hline H18W6 & 60.32 & 13.87 & 107.31 & 51.31 & 91.21 & 55.43 \\
\hline H12D3 & 57.63 & 14.76 & 101.63 & 55.56 & 86.38 & 59.49 \\
\hline F12D3 & 56.46 & 13.92 & 122.47 & 43.67 & 104.09 & 48.62 \\
\hline
\end{tabular}

Table 4. Ductility coefficients of connection specimens.

\begin{tabular}{|c|c|c|c|c|c|c|}
\hline $\begin{array}{c}\text { Connection } \\
\text { Specimen }\end{array}$ & $\begin{array}{c}\text { Yield } \\
\text { Displacement } \\
\boldsymbol{D}_{\mathbf{y}}(\mathbf{m m})\end{array}$ & $\begin{array}{c}\text { Ultimate } \\
\text { Displacement } \\
\boldsymbol{D}_{\mathbf{u}}(\mathbf{m m})\end{array}$ & $\begin{array}{c}\text { Yield } \\
\text { Displacement } \\
\text { Angel } \boldsymbol{\theta}_{\mathbf{y}}\end{array}$ & $\begin{array}{c}\text { Failure } \\
\text { Displacement } \\
\text { Angel } \boldsymbol{\theta}_{\mathbf{u}}\end{array}$ & $\begin{array}{c}\text { Displacement } \\
\text { Ductility } \\
\text { Ratio } \boldsymbol{\mu}\end{array}$ & $\begin{array}{c}\text { Rotational } \\
\text { Ductility } \\
\text { Coefficient } \boldsymbol{\mu}_{\boldsymbol{\theta}}\end{array}$ \\
\hline \hline H18D3 & 17.92 & 58.33 & 0.0145 & 0.0477 & 3.27 \\
\hline H18W3 & 18.28 & 59.43 & 0.0145 & 0.0499 & 3.25 & 3.29 \\
\hline H18D6 & 16.98 & 54.52 & 0.0118 & 0.0392 & 3.24 & 3.26 \\
\hline H18W6 & 16.87 & 54.65 & 0.0126 & 0.0425 & 3.23 \\
\hline H12D3 & 14.76 & 59.49 & 0.0121 & 0.04418 & 3.23 & 3.24 \\
\hline F12D3 & 13.92 & 48.62 & 0.0119 & 0.04388 & 3.21 \\
\hline
\end{tabular}

ring plate, and the installation of backing plate as well as the shape change of ring plate from square to circle can improve the ductility of connection significantly. Moreover, the ductility of connection specimens decreases with the augment of axial compression ratio.

\subsection{Characteristics of Stiffness Degradation}

Fig. (7) illustrates the comparisons of stiffness degradation curves of connection specimens. From the comparative curves, it can be found that the degradation tendency is much more defined for the connection specimens with larger size of ring plates and higher axial compression ratio. The backing plates have the similar effect on the degradation tendency of connection specimens. And it coincides with the indications of skeleton curves above, that the specimen with square ring plates displays a more evident degradation tendency than ones with circular ring plates. That is also to say the specimen with square ring plate presents better bearing capacity but lower deformation capacity.

\subsection{Characteristics of Strain Distribution and Variation with Load}

The strain versus load relationships at typical points in connection specimens are shown in Fig. (8). Generally, when load values are more than $\pm 50 \mathrm{kN}$, the strains variation, at typical points in connection specimen with load, begin to present different tendencies. And when load values are more than $\pm 80 \mathrm{kN}$, plastic strains at typical points in connection specimen occur. Furthermore, when load values are more than $\pm 100 \mathrm{kN}$, the strains at typical points in connection specimen reach the state of hardening plasticity until the specimens' failure. Especially, plastic strains at typical point 2 and point 49 augment with great increments than the strains at the other points. Integrated with Fig. (2), it can also be seen that there are clear stress concentrations in the position of high-strength steel bolt holes and nearby area of beam flange for the given connection specimens.

\section{CONCLUSION}

In the present work, a new type of design of cross-shaped connection with CFST column and assembled steel H-beam was investigated based on experimental analyses. For the connections specimens are studied, several conclusions are drawn as follows.

The presented CFST column connection is of convenient for contsruction and fine deformation performance compared with the CFST column connections by welding technique. It can satisfy the strength needs and can be applied into future construction by further local optimization in detail.

There are clear stress concentrations in the position of high-strength steel bolt holes and nearby area of beam flange for the given connection specimens. Special importance should be given to corresponding constructional techniques and installations for good quality.

The increase of width of ring plate and the shape change of ring plate from square to circle can both improve the ductility and the characteristics of hysteretic behavior of connection significantly. It is emphasized that the specimen with square ring plates is of better deformation performance but lower bearing capacity than the ones with circular ring plates. 
(a)

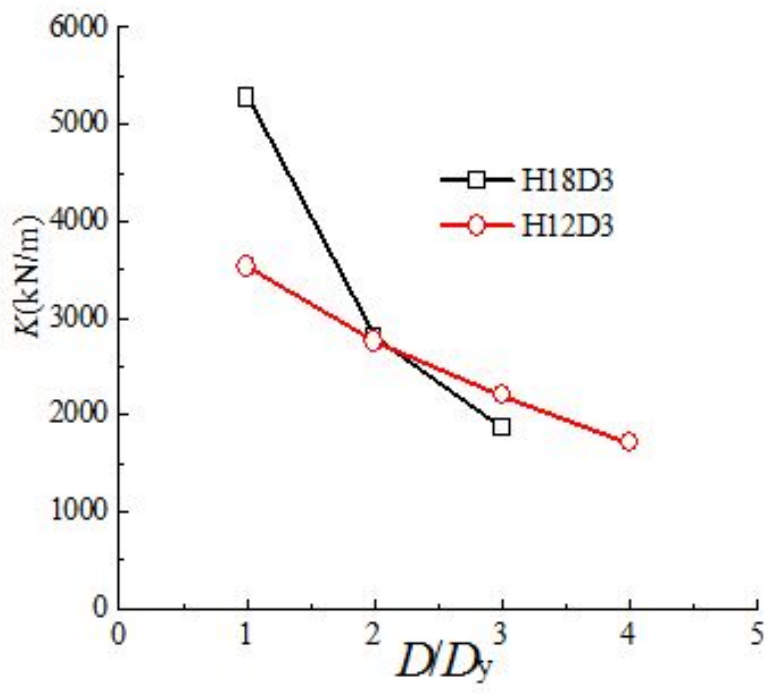

(c)

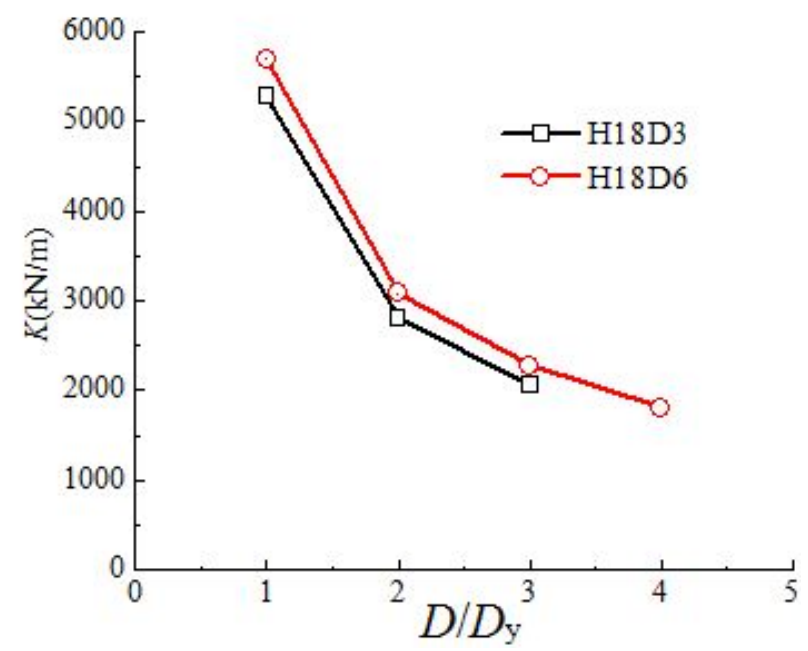

(e)

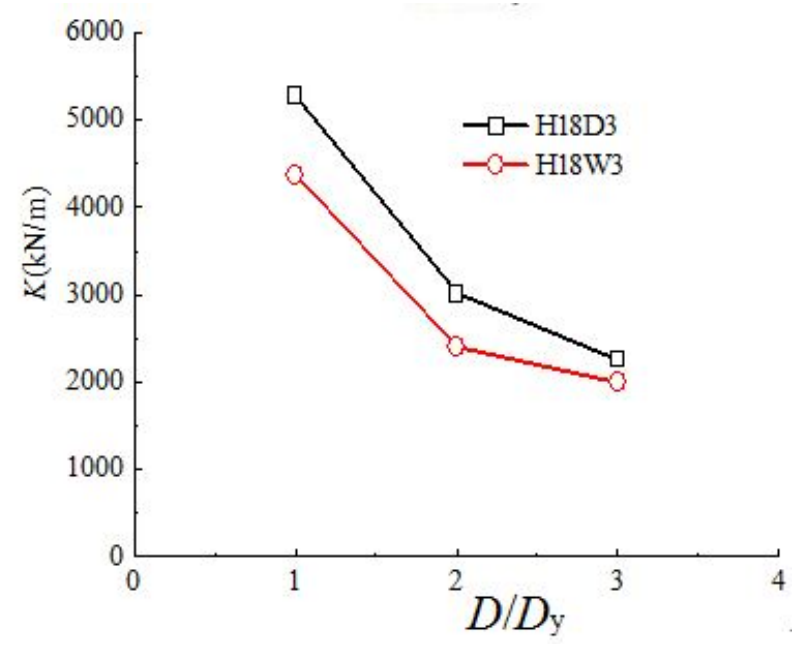

Fig. (7). Comparisons of stiffness degradation curves.

The backing plates have positive effects on the hysteretic characteristics, ductility and energy dissipation of the CFST column connections. It is supposed to be installed in the application for economic considerations and construction (b)

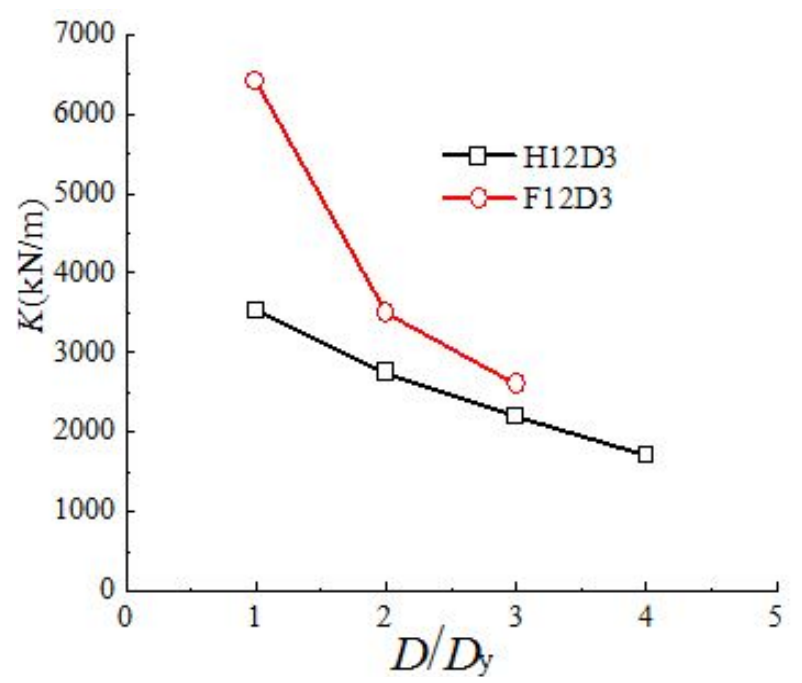

(d)

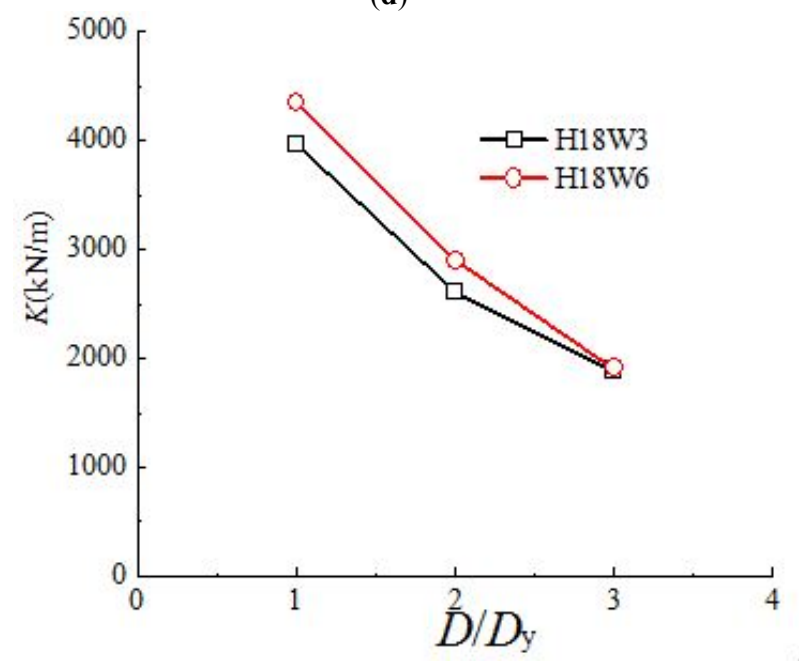

(f)

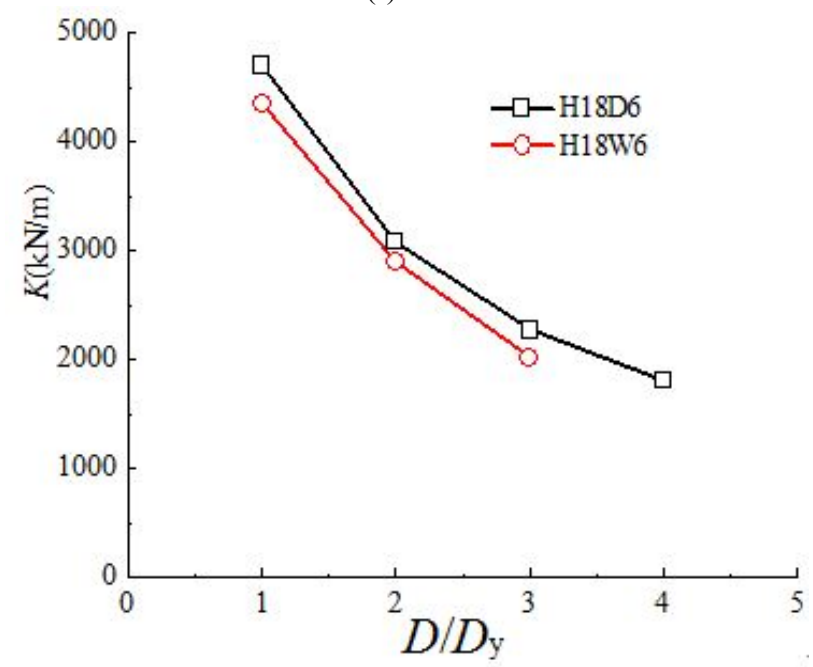

convenience. Conversely, the increase of axial compression ratio contributes negatively to both the bearing capacity and deformation performance of the connection specimens. 
(a) H18D3

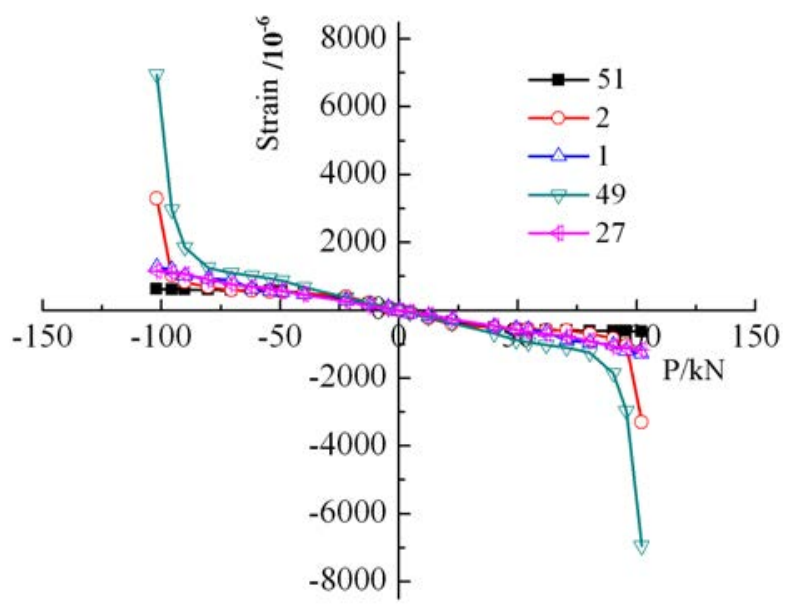

(c) H18D6

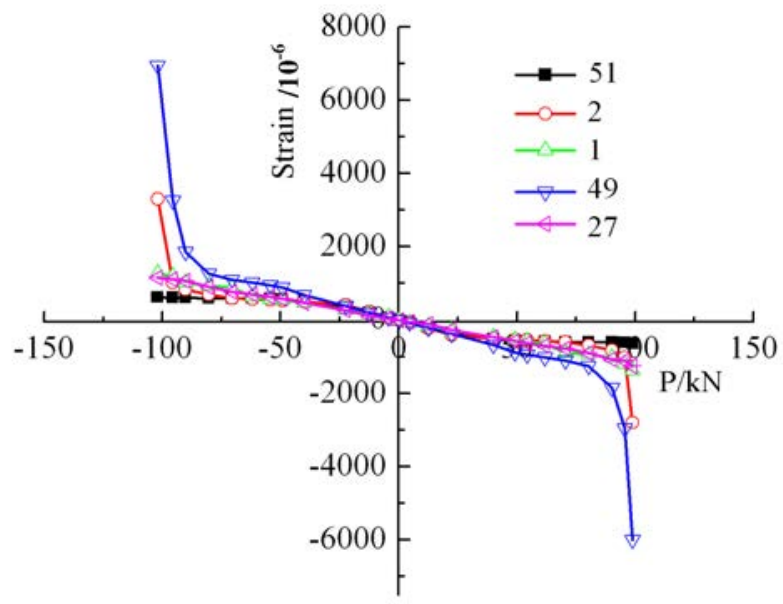

(e) H12D3

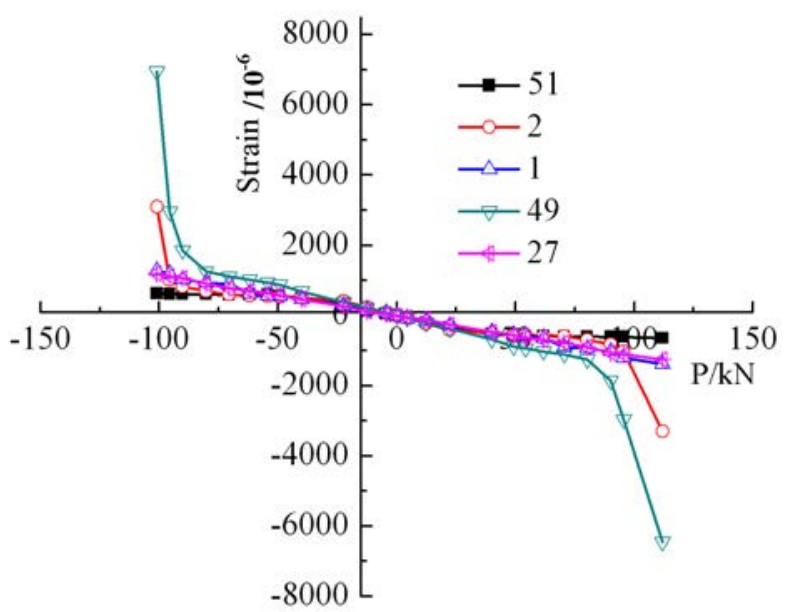

(b) H18W3

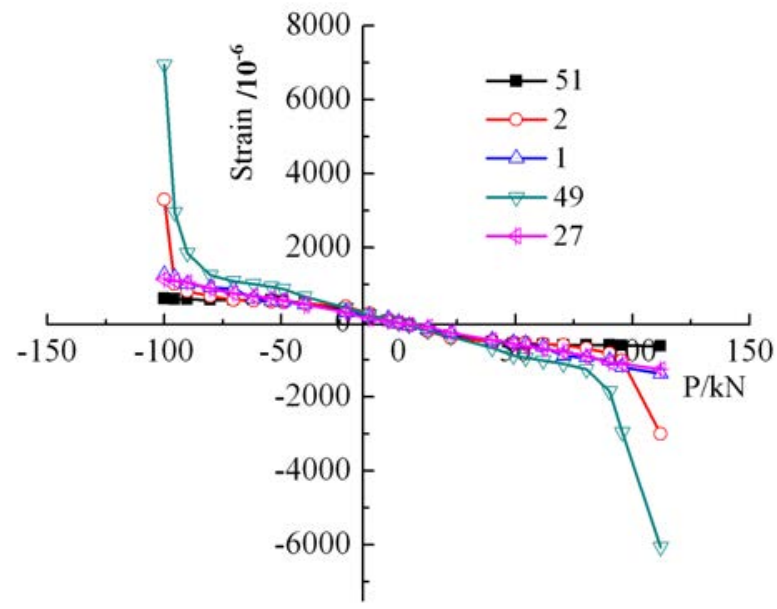

(d) H18W6

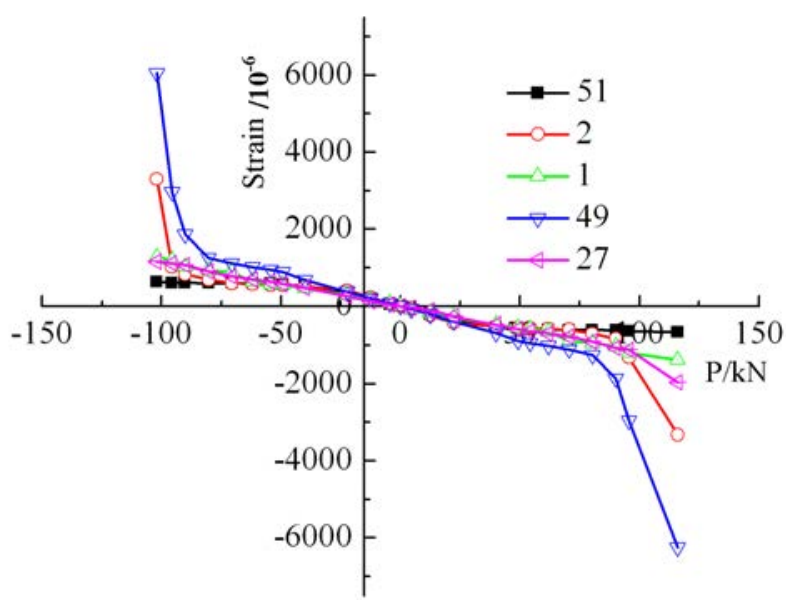

(f) F12D3

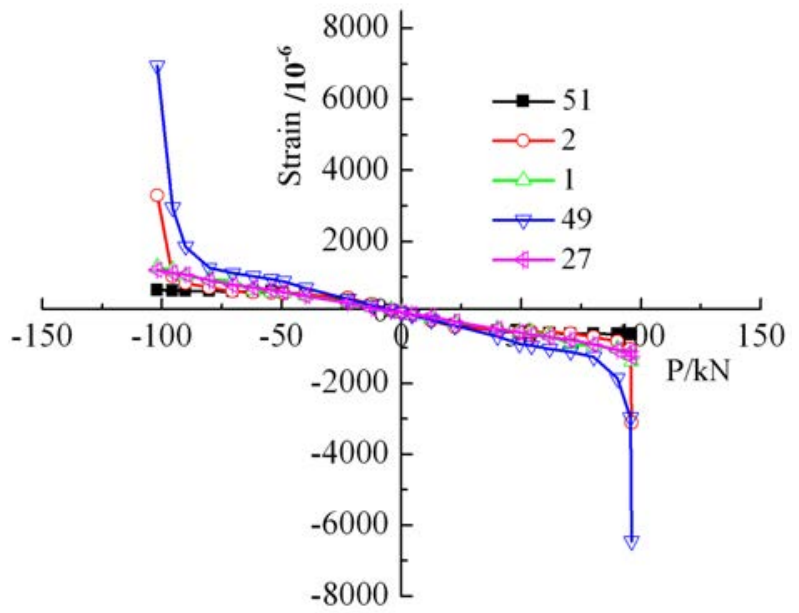

Fig. (8). Strain versus load relationships of typical points in connection specimens.

\section{CONFLICT OF INTEREST}

The authors confirm that this article content has no conflict of interest.

\section{ACKNOWLEDGEMENTS}

This research was financially supported by a Grant from National Natural Science Foundation of China (No 50809009) and a Grant from the Fundamental Research Funds for the Central Universities (No 3132014072). 


\section{REFERENCES}

[1] D. Martin, O. Shear, and Q. Russell, "Bridge Design of circular thin-walled concrete filled steel tubes", Journal of Structural Engineering, vol. 126, no. 11, 725-758, 2012.

[2] S. Kyung-Jae, K. Young-Ju, O. Young-Suk, and M. Tae-Sup, "Behavior of welded CFT column to H-beam connections with external stiffeners", Engineering Structures, vol. 26, 1877-1887, 2004.

[3] L. Han, "Theory and practice of concrete filled steel tubular structure", 2nd edition. Beijing: Science Press, 2007.

[4] J.M. Ricles, S.W. Peng, and L.W. Lu, "Seismic behavior of composite concrete filled steel tube column-wide flange beam moment connections", Journal of Structural Engineering, vol. 130, no. 2, 233-243, 2004.

[5] M. Gregory, W. R. Charles, G. Chad, and K. Yoshihiro, "BraceBeam-Column connections for concentrically braced frames with concrete filled tube columns", Journal of Structural Engineering, vol. 16, 233-243, 2004.

[6] S. Morino, J. Kawaguchi, and C. Yasuzaki, et al. "Behavior of concrete filled steel tubular three-dimensinal sub assemblages", Composite Construction in Steel and Concrete II[C]. Potos, $i$ Missouri, 1993, 726-741.

[7] M. Teraoka, and K. Morita, "Experimental study on structural behavior of concrete-filled square tubular column in steel H-beam connections without diaphragm", Proceeding of the $4^{\text {th }}$ ASCCS International Conference on Steel-concrete Composite Structures[C]. Kosice, slovakia, 1994, 190-193.

[8] J.E. France, J. B. Davison, and P. A. Kirby, "Moment-capacity and rotational stiffness of endplate connections to concrete filled tubular columns with flowdrilled connectors", Journal of Constructional Steel Research, vol. 50, 35-48, 1999.
[9] J. Beutel, D. Thambiratnam, and N. Perera, "Cyclic behavior of concrete filled steel tubular column to steel beam connections", Engineering Structures, vol. 4, no. 11, 29-38, 2002.

[10] C.Y. Li, Y.J. Guo, M.D. Li, "Experimental study on rigidity of concrete filled steel tubular external strengthening ring node", Industrial Building, vol. 6, no. 9, 81-83, 2006.

[11] S. M. Zhang, and D. X. Zhang, "Load-displacement hysteretic curve theory analysis of reinforced concrete column and beam joint", Journal of Harbin University of Civil Engineering and Architecture, vol. 34, no. 4, 1-6, 2001

[12] J. Chen, Z. Wang, and J. X. Yuan, "Research on the stiffness of concrete filled tubular column and steel beam joint with stiffening ring”, Journal of Building Structures, vol. 25, no. 4, 43-54, 2004.

[13] C.T. Cheng, P.S. Hwang, L. Y. Lu, and L. L. Chung. Connection behavior of steel beam to concrete-filled circular steel tubes. Proceeding of 6th ASCCS Conference, Los Angeles, USA, 2000, 81-589.

[14] S. P. Chiew, S. P. Lie, and C. W. Dai, "Moment Resistance of Stee I-Beam to CFT Column Connections", Journal of Structural Engineering, vol. 127, no. 10, 1164-1172, 2001

[15] C. H. Kang, K. J. Shin, Y. S. Oh, et al. "Hysteresis behavior of CFT column to H-beam connections with external T-stiffeners and penetrated element", Engineering Structures, vol. 23, 1194-1201, 2001.

[16] L. H. Xu, H. Fan, and S. B. Liu, et al. Experimental studies on aseismic behavior of connection between concrete-filled steel square tubular column and steel beam", Engineering Mechanics, vol. 25 , no. $2,122-131,2008$.

[17] L.H. Han, "Theory and practice of concrete filled steel tubular structure", 2nd edition. Beijing: Science Press, 2007. 